\title{
Inelastic Versus Elastic Displacement-Based Intensity Measures for Seismic Analysis
}

\author{
L. Lin and Y. L. Gao, Member, IACSIT
}

\begin{abstract}
Intensity measure (IM) is a parameter that is used to scale the records for the time-history analysis of a structure subjected to seismic loads. It is well known that the accuracy of the seismic response of the structure depends very much on IM. This paper presents a study on the use of the inelastic displacement as IM for the nonlinear time-history analysis. For the purpose of the study, three reinforced concrete moment-resisting frame buildings (4-, 10-, and 16-storey high) designed for Vancouver, Canada were used in the analysis. The buildings were subjected to the total number of 40 records scaled to five intensity levels which represent a global ductility of 1 to 5 . Based on the results from the analysis, it was found out that the inelastic displacement does not have advantage over the elastic displacement (or the spectral acceleration) as IM.
\end{abstract}

Index Terms-Dispersion, elastic displacement, inelastic displacement, intensity measure.

\section{Motivation}

There are several studies in which the inelastic spectral displacement at the fundamental structural period, $T_{1}$ (i.e., $\left.\operatorname{Sdi}\left(T_{1}\right)\right)$, has been used as an intensity measure $(I M)$, e.g. [1], [2]. For a given building, the inelastic spectral displacement (Sdi) is computed for an equivalent bilinear single-degree-of-freedom (SDOF) system that has the same elastic period as the fundamental period of the building, and provides displacement responses to ground motions that are similar to the roof displacements of the building. The same as $S a\left(T_{1}\right), S d i$ does not include the contributions of the higher modes to the response of the structure. However, Sdi is intended to take into account the effects of the elongation of the fundamental period during nonlinear response. This is because the period of the equivalent SDOF system elongates during the response, and therefore Sdi depends, to some extent, on the ground motion spectral characteristics for periods longer than the elastic period of the SDOF system.

The objective of this study was to assess the potential use of $S d i$ as $I M$. This was done by investigating the seismic responses of three reinforced concrete frame buildings (4-, 10-, and 16-storey high) located in Vancouver, Canada subjected to a selected set of records scaled to different intensity levels. The dispersions of the interstorey drifts resulting from $S d i$ were compared to those from $S d e$ (elastic spectral displacement) to know the suitability of using $S d i$ as $I M$ for the seismic analysis of buildings. Note that the elastic spectral displacement $(S d e)$ for a given period, $T_{1}$, is linearly

Manuscript received March 8, 2014; revised May 12, 2014.

The authors are with Concordia University, Canada (e-mail: lan.lin@concordia.ca, gaoyuling1119@hotmail.com). proportional to the elastic spectral acceleration $(\mathrm{Sa})$ for that period (i.e., $S d e=\left(T_{1} / 2 \pi\right)^{2} \cdot S a$ ), and therefore, $S d e$ and $S a$ represent the same $I M$. For convenience, however, $S d e$ rather than $S a$ is used in this study.
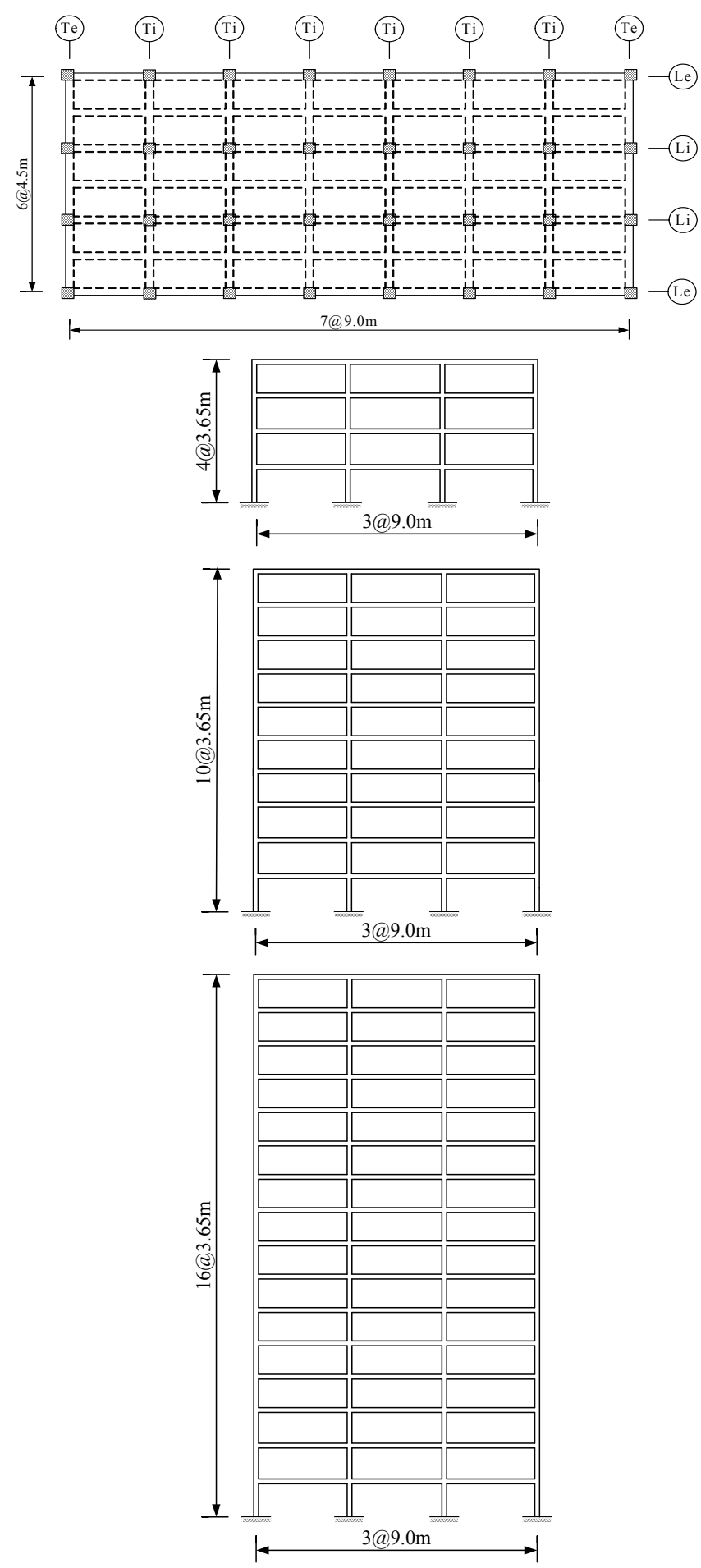

Fig. 1. Plan of floors and elevations of transverse frames of the buildings. 


\section{DESCRIPTION OF BUILDINGS AND DESIGN PARAMETERS}

Three reinforced concrete frame buildings, 4-, 10-, and 16-storey, were used in the study (Fig. 1). The buildings are for office use and are located in Vancouver, which is in a high seismic hazard zone in Canada [3]. These buildings are used to represent the behaviour of low-rise, medium-rise, and high-rise buildings, respectively. As shown in Fig. 1, the buildings are identical in plan but have different heights. The plan of each building is $27.0 \mathrm{~m}$ x $63.0 \mathrm{~m}$. The storey heights are $3.65 \mathrm{~m}$. The lateral load resisting system consists of moment-resisting reinforced concrete frames in both the longitudinal and the transverse directions. There are four frames in the longitudinal direction (designated $L e$ and $L i$ in Fig. $1 ; L e-$ exterior frames, and $L i-$ interior frames) and eight frames in the transverse direction ( $T e$ and $T i$ ). The distance between both the longitudinal and the transverse frames is $9.0 \mathrm{~m}$. Secondary beams between the longitudinal frames are used at the floor levels to reduce the depth of the floor slabs. The secondary beams are supported by the beams of the transverse frames. The floor system consists of a one-way slab spanning in the transverse direction, supported by the beams of the longitudinal frames and the secondary beams. The slab is cast integrally with the beams. In this study, the interior transverse frames $\left(T_{i}\right)$ of the buildings were considered. For ease of discussion, the 4-storey, the 10-storey, and the 16-storey frames are referred to as the $4 \mathrm{~S}$, the $10 \mathrm{~S}$, and the $16 \mathrm{~S}$ frames, respectively.

The frames were designed as ductile reinforced concrete frames in accordance with the 2005 edition of the National Building Code of Canada (NBCC) [4]. It is necessary to mention that the design would not change if $2010 \mathrm{NBCC}$ were used. The design base shears were calculated using the seismic design spectrum for Vancouver. The foundations were assumed to be on stiff soil represented by site class $\mathrm{C}$ in NBCC (shear wave velocity between $360 \mathrm{~m} / \mathrm{s}$ and $750 \mathrm{~m} / \mathrm{s}$ ). The fundamental periods of the frames were calculated according to the code formula, $T_{a}=0.075 h_{n}{ }^{3 / 4}$, where $h_{n}$ is the height of the frame above the base in metres. The other parameters used in the calculation of the base shears were the ductility-related force modification factor $R_{d}=4$, the overstrength-related force modification factor $R_{o}=1.7$, the higher mode factor $M_{V}=1$, and the importance factor $I_{E}=1$. Compressive strength of concrete $f_{c}^{\prime}=30 \mathrm{MPa}$, and yield strength of reinforcement $f_{y}=400 \mathrm{MPa}$ were used in the design. The dimensions of the beams and columns, and the reinforcement obtained from the design are given in [5].

\section{MODELING OF FRAMES FOR DYNAMIC ANALYSIS}

Inelastic models of the frames were developed for use in the two-dimensional (2D) inelastic dynamic analysis program RUAUMOKO [6]. The beams and the columns were modelled by a beam-column element, which is represented by a single component flexural spring. Inelastic deformations are assumed to occur at the ends of the element where plastic hinges can be formed. The effects of axial deformations in beams are neglected. Axial deformations are considered for columns, but no interaction between bending moment and axial load is taken into account.
For the purpose of the frame models, moment-curvature relationships for the end sections of each beam and column were computed using the stress-strain model for confined concrete proposed by [7]. Nominal values for material strengths (i.e., concrete and reinforcement resisting factors $\Phi_{c}=\Phi_{s}=1$ ) were used in the computation of the moment-curvature relationships. Based on the shapes of the moment-curvature relationships, a trilinear hysteretic model was selected for the columns, and a bilinear (modified Takeda) model was selected for the beams (Fig. 2). Both models take into account the degradation of the stiffness during nonlinear response. The parameters of the trilinear model for each column were based on the computed moment-curvature relationships. Values for the coefficients $a$ and $b$ of 0.5 and 0.6 , respectively, were used for the bilinear model (Fig. 2b) as suggested by [6]. Table I shows the natural periods of the first two vibration modes of the frames obtained by RUAUMOKO.
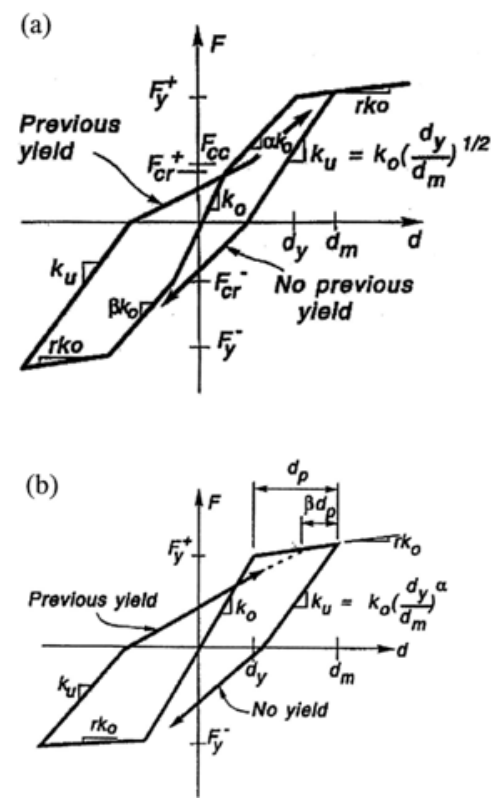

Fig. 2. Hysteretic models used in the study: (a) for columns, (b) for beams (Adopted from [6]).

TABLE I: NATURAL PERIODS OF THE FRAME MODELS (IN SECONDS).

\begin{tabular}{cccc}
\hline \multirow{2}{*}{ Frame model } & \multicolumn{3}{c}{ Mode No. } \\
\cline { 2 - 4 } & 1 & 2 & 3 \\
\hline $4 \mathrm{~S}$ & 0.94 & 0.29 & 0.14 \\
$10 \mathrm{~S}$ & 1.96 & 0.70 & 0.40 \\
$16 \mathrm{~S}$ & 2.75 & 1.02 & 0.60 \\
\hline
\end{tabular}

\section{SElECTION OF EARTHQUAKE RECORDS}

Ground motion records from earthquakes in the Vancouver region would be the most suitable for this study. Since such records are not available, recorded ground motions from earthquakes in California were selected. It is commonly accepted that the characteristics of earthquakes that might occur in the Vancouver region are similar to those of Californian earthquakes [8]. A set of 40 earthquake records was selected from the strong motion database of the Pacific. 


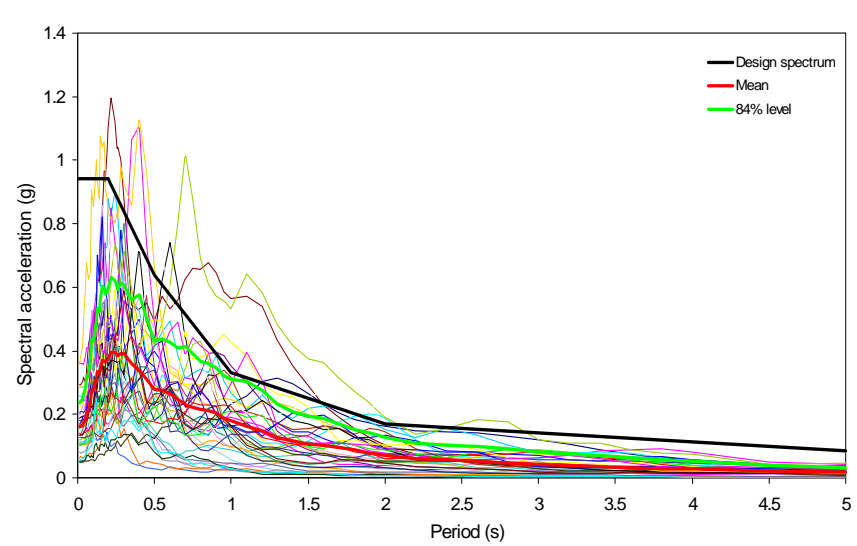

Fig. 3. Acceleration response spectra for the selected records, $5 \%$ damping.

Earthquake Engineering Research (PEER) Center. The records are obtained at sites with shear wave velocities between $360 \mathrm{~m} / \mathrm{s}$ and $750 \mathrm{~m} / \mathrm{s}$ (i.e., NBCC site class C, which was assumed in the design of the buildings). The records are obtained from 9 earthquakes with magnitudes between 6.0 and 7.4 , at distances from $11.3 \mathrm{~km}$ to $90.6 \mathrm{~km}$. Both the magnitude and the distance ranges cover the magnitudes and the distances of the earthquakes that have the largest contributions to the seismic hazard for Vancouver, reported in [9] and [10]. The peak accelerations of the records range from $0.10 \mathrm{~g}$ to $0.28 \mathrm{~g}$. Fig. 3 shows the $5 \%$ damped acceleration spectra of the records. The NBCC design spectrum for Vancouver is also included in the figure. It is seen in Fig. 3 that the spectra of the records are below the design spectrum, which is expected because the design spectrum is defined to be conservative. More detailed information for the earthquakes and the records can be found in $\operatorname{Lin}[5]$.

\section{EquiVAlENT INELASTIC SDOF SyStEMS FOR THE FRAMES}

For the purpose of the study, equivalent inelastic SDOF systems were developed for the frames. These were needed to determine the scaling factors for the records scaled to Sdi. The method proposed by [11] for the development of an equivalent inelastic SDOF system for a multi-degree-of-freedom (MDOF) system was used in this study. The SDOF system was assumed to follow elastic-perfectly plastic force-displacement relationship. The method is developed to simplify the computation of the nonlinear response of MDOF structures. Namely, the top (i.e. roof) displacement response of a building structure subjected to a given ground motion can be determined approximately from the displacement response of the idealised SDOF system under the same motion. Detailed derivations of the parameters of the equivalent SDOF system are presented in [11], and only the final expressions are given in this paper.

For each frame, the parameters of the inelastic SDOF system (designated with ${ }^{*}$ ) were determined as follows:

- $\quad$ Equivalent mass $m^{*}=\Sigma m_{i} \Phi_{i}$, where $m_{i}$ is the mass of the frame at floor level $i$, and $\Phi_{i}$ is the value of the first mode shape $\Phi$ at level $i$; note that $\Phi$ is normalized to have a value of 1 at the roof.
- $\quad$ Yield displacement $D_{y}{ }^{*}=D_{y}{ }^{t} / \Gamma$, and yield strength $F_{y}{ }^{*}=V_{y} / \Gamma$, where $D_{y}{ }^{t}$ and $V_{y}$ are the top displacement and the base shear respectively, corresponding to the yield point of the idealised pushover curve for the frame (Fig. 4 ), and $\Gamma=m^{*} / \Sigma m_{i} \Phi_{i}{ }^{2}$. The pushover curve for each frame was determined using the program RUAUMOKO.

- The elastic period of the equivalent SDOF system is $T^{*}=2 \pi \sqrt{m^{*} D_{y}^{*} / F_{y}^{*}}$. Note that this is very close to the fundamental period $\left(T_{1}\right)$ of the frame considered, and can be assumed that $T^{*}=T_{1}$; the proximity comes from the idealisation of the pushover curves (Fig. 4).

Having determined the parameters of the SDOF system for a given frame, the maximum value of the top (roof) displacement $\left(D_{\max }^{t}\right)$ of the frame subjected to a specified ground motion can be expressed as [11]:

$$
D_{\max }^{t}=\Gamma \cdot S d
$$

where $\Gamma$ is as defined above, and $S d$ represents spectral displacement which can be elastic (if the maximum displacement response of the SDOF system is smaller than $D_{y}^{*}$ ), or inelastic (if the SDOF system response is larger than $\left.D_{y}^{*}\right)$.

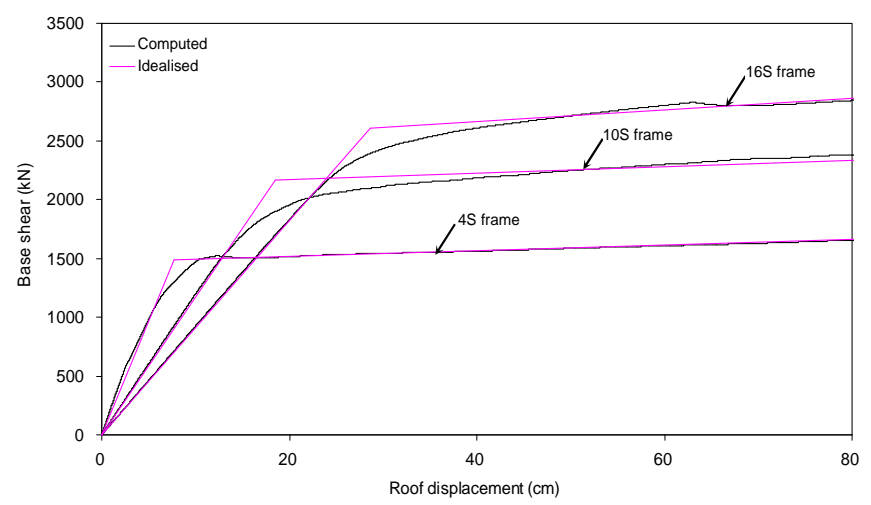

Fig. 4. Pushover curves for the frames.

\section{ANALYSIS AND RESULTS}

The frames were analysed using the records selected from the PEER database as excitation motions. For the purpose of comparisons, analyses were conducted by scaling the records to elastic spectral displacements $S d e$, and to inelastic spectral displacements $S d i$.

Scaling to Sde is straightforward, and therefore the discussion that follows is primarily related to the scaling to $S d i$. Scaling to $S d i$ requires considerations of the equivalent inelastic SDOF system of the frame that is analysed, and therefore it is useful to discuss briefly the expected response of the frame relative to the characteristics of the equivalent SDOF system.

Theoretically, based on Equation (1) and the expressions used in the derivation of the equivalent SDOF system for a given frame, one might expect elastic responses of the frame for records scaled to $S d \leq D_{y}{ }^{*}$ and inelastic responses for records scaled to $S d>D_{y}{ }^{*}$ (as mentioned above, $S d$ denotes spectral displacement, in general, which can be elastic or inelastic). However, considering the assumptions and the 
approximations involved in the derivation of the equivalent SDOF system, the frame could experience inelastic responses for scaling to $S d$ levels even well below $D_{y}{ }^{*}$. For simplicity, however, and following the practice in other studies [3], the scaling in this study was based on $S d i$ for scaling levels $S d>D_{y}^{*}$.

In this study, $S d=D_{y}{ }^{*}$ is called the reference spectral displacement, and is designated as $S d_{\text {ref }}$. It represents (approximately) the highest scaling level associated with elastic responses of the frames. In other words, records scaled to $S d_{\text {ref }}$ are expected to produce responses corresponding to an average 'global' displacement ductility of approximately 1.0 , where the 'global' ductility is represented by the ratio of the maximum roof displacement $\left(D_{\max }^{t}\right)$ obtained from nonlinear dynamic analysis of the frame to the 'global' yield displacement $\left(D_{y}^{\mathrm{t}}\right)$ from the pushover curve (Fig. 4) (i.e., $\left.D_{\max }^{t} / D_{y}{ }^{t}\right)$. The values for $S d_{\text {ref }}$ for the $4 \mathrm{~S}$, the $10 \mathrm{~S}$, and the $16 \mathrm{~S}$ frames are listed in Table II. The $S a_{r e f}$ in the table is computed as $S a_{r e f}=\left(2 \pi / T_{1}\right)^{2} \cdot S d_{r e f}$.

Five intensity levels were used in the analysis, i.e., $S d=S d_{\text {ref }}$ to $S d=5 S d_{\text {ref }}$, which were intended to produce 'global' ductilities of approximately 1.0 to 5.0 respectively. For each intensity level, the records were scaled to both the $S d e$ and Sdi. While the scaling to $S d e$ is routine, the scaling to $S d i$ required a number of nonlinear time history analyses of the equivalent SDOF systems of the frames in order to determine the scaling factors for each of the intensity levels considered. Namely, for a given frame and intensity level, the scaling factor for each record was determined by incrementally increasing the intensity of the record (i.e., by increasing the scaling factor) and conducting time history analyses on the equivalent SDOF system of the frame until the computed inelastic displacement of the SDOF system matched the prescribed intensity level.

TABLE II: REFERENCE VALUES FOR SPECTRAL DISPLACEMENT ( $S D_{R E F}$ ) AND SPECTRAL ACCELERATION $\left(S A_{\text {REF }}\right)$ FOR THE 4 S, THE $10 \mathrm{~S}$, AND THE 16S FRAMES.

\begin{tabular}{ccc}
\hline Frame & $\begin{array}{c}\text { Reference spect. } \\
\text { displac. } \\
\mathrm{Sd}_{\text {ref }}(\mathrm{cm})\end{array}$ & $\begin{array}{c}\text { Reference spect. } \\
\text { accel. } \mathrm{Sa}_{\text {ref }}(\mathrm{g})\end{array}$ \\
\hline $4 \mathrm{~S}\left(T_{1}=0.94 \mathrm{~s}\right)$ & 4.0 & 0.18 \\
$10 \mathrm{~S}\left(T_{1}=1.96 \mathrm{~s}\right)$ & 13.4 & 0.14 \\
$16 \mathrm{~S}\left(T_{1}=2.75 \mathrm{~s}\right)$ & 20.5 & 0.11 \\
\hline
\end{tabular}

Finally, time history analyses were conducted on the frames using the scaled records as excitation motions. Maximum interstorey drifts $(I D R)$ over the height of the frames were determined for each excitation. Fig. 5, Fig. 6, and Fig. 7 show the maximum interstorey drifts for the 4S, the $10 \mathrm{~S}$, and the $16 \mathrm{~S}$ frames respectively. The figures contain the results from the scaling to $S d e$ (graphs (a) in the figures), and those from the scaling to Sdi (graphs (b)). The 50\% (i.e., the median), the $84 \%$, and the $16 \%$ levels of the results are also shown in the figures.

The main objective of this investigation is to compare the dispersions of the responses for scaling to Sde and Sdi. The dispersion is an important indicator for the effectiveness of a given $I M$, i.e., smaller dispersion is always preferred [12]. The dispersions of the interstorey drifts of the frames can be assessed by considering the bands between the $84 \%$ and the $16 \%$ levels of the results in Fig. 5, Fig. 6, and Fig. 7. It is seen in the figures that the dispersions resulting from scaling to $S d e$ and $S d i$ are quite close. This indicates that considering the dispersions, the use of $S d i$ as $I M$ does not have advantage compared to the use of $S d e$, for the frames used in this study.
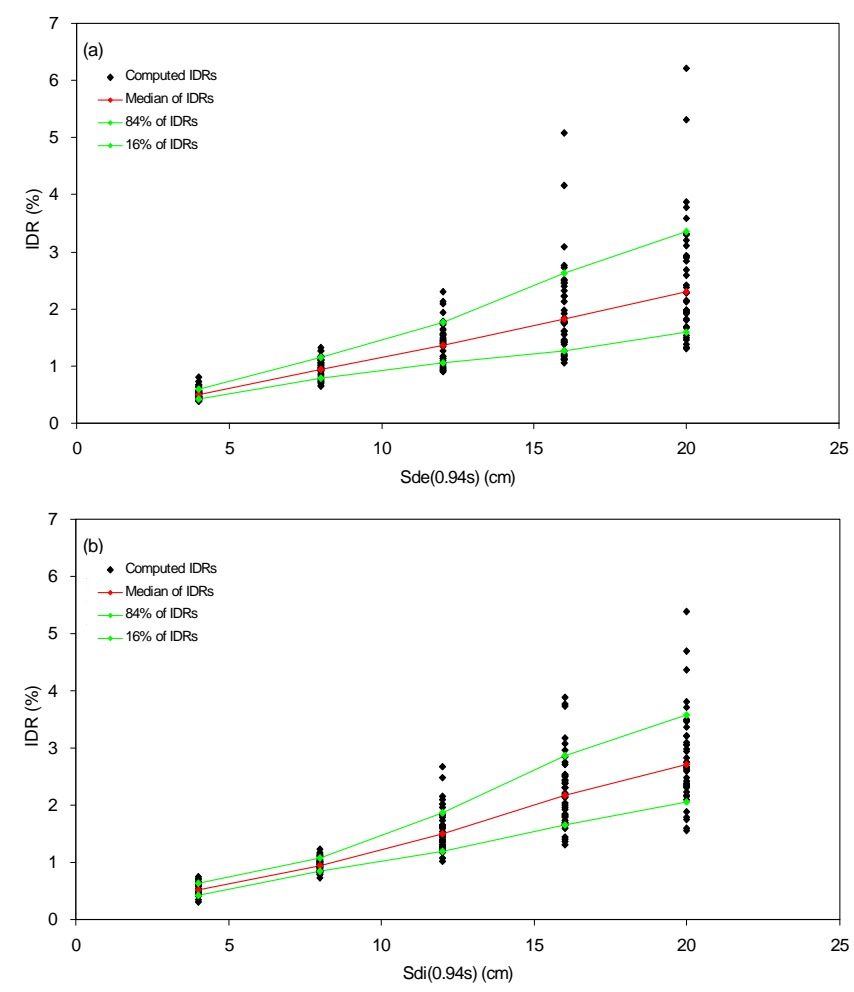

Fig. 5. Variation of interstorey drifts for the $4 \mathrm{~S}$ frame for intensity measures represented by elastic and inelastic spectral displacements, i.e., Sde and Sdi respectively: (a) $S d e$, and (b) $S d i$.
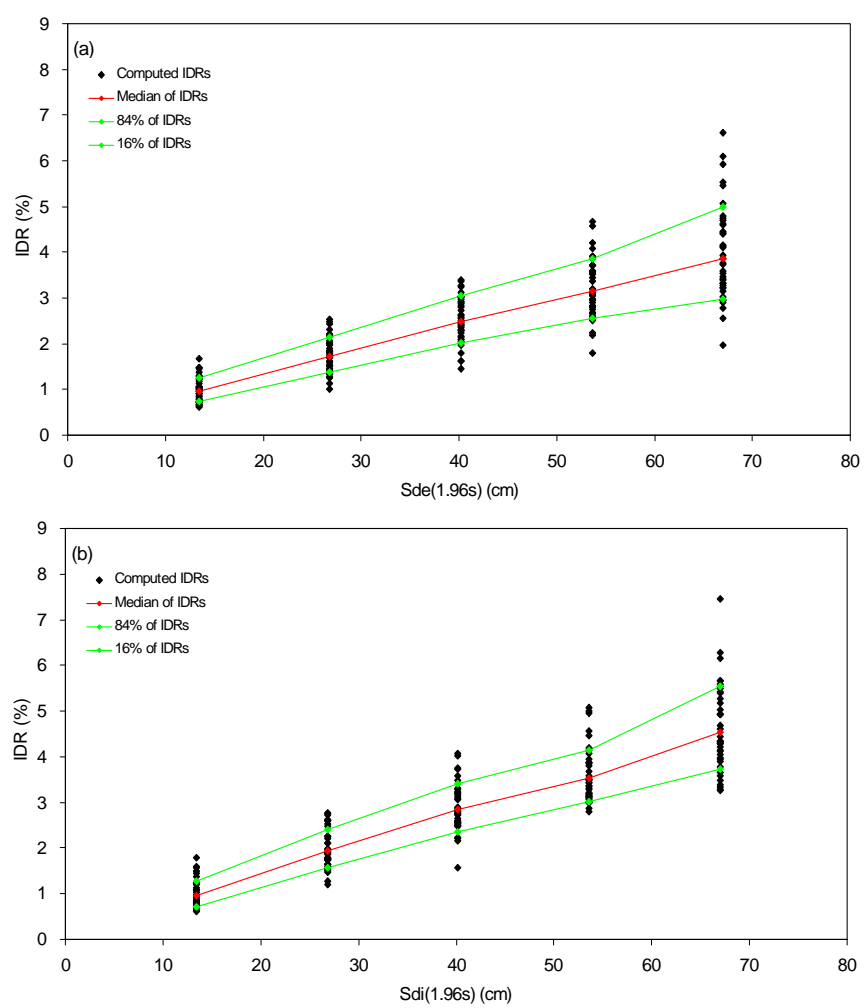

Fig. 6. Variation of interstorey drifts for the $10 \mathrm{~S}$ frame for intensity measures represented by elastic and inelastic spectral displacements, i.e., Sde and Sdi respectively: (a) $S d e$, and (b) $S d i$. 

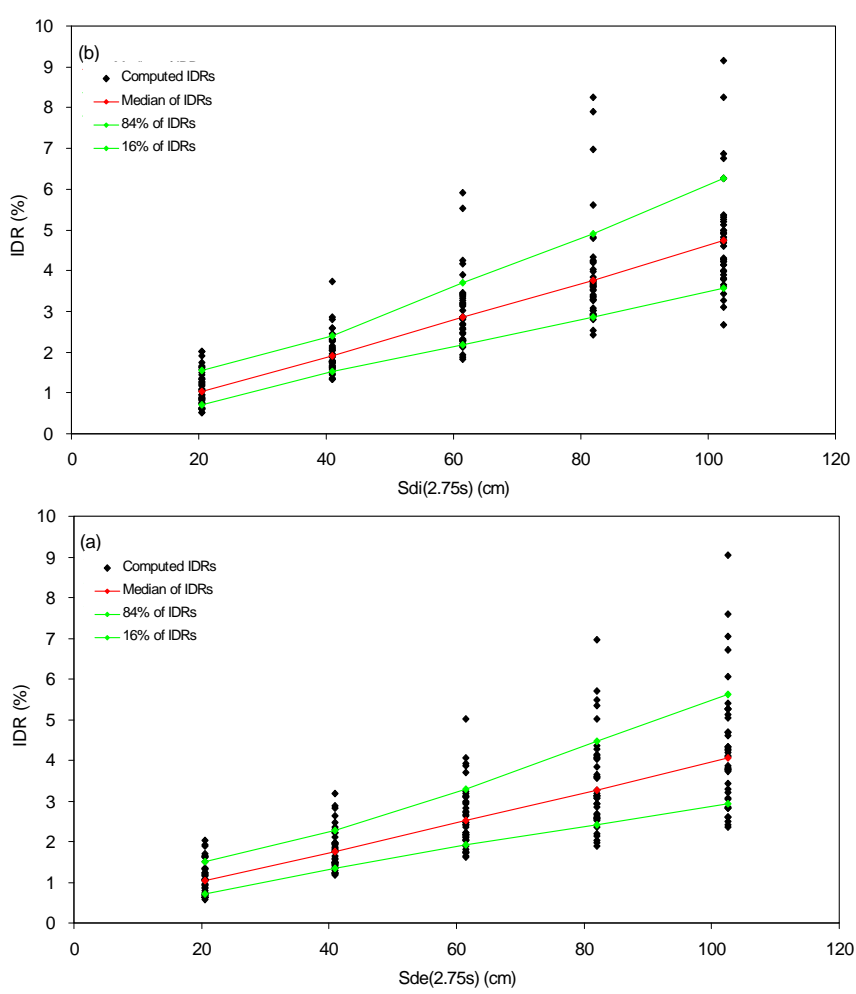

Fig. 7. Variation of interstorey drifts for the $16 \mathrm{~S}$ frame for intensity measures represented by elastic and inelastic spectral displacements, i.e., Sde and Sdi respectively: (a) $S d e$, and (b) $S d i$.

\section{CONCLUSIONS}

An investigation was conducted to determine the effects of the use of elastic and inelastic spectral displacements (Sde and $S d i$ respectively) as intensity measures. Time-history analyses were performed on the three reinforced concrete ductile frame buildings located in Canada. The buildings are 4-, 10-, and 16-storey high, and they are for office use. In total, 40 records selected from the PEER database were used in the time-history analysis. The records were scaled to Sde and $S d i$. The inelastic spectral displacement $(S d i)$ was determined based on the equivalent SDOF for a MDOF system while the elastic spectral displacement $(S d e)$ for a given period $T_{1}$ was computed using the elastic spectral acceleration $(S a)$ for that period (i.e., $S d e=\left(T_{1} / 2 \pi\right)^{2} \cdot S a$ ). Among a number of response parameters from the analysis, interstorey drift was used to represent the seismic response of the buildings considered in this study. The dispersions of the maximum interstorey drifts of the frames from scaling to Sde and $S d i$ were compared to see which of these two parameters is more appropriate for scaling. The dispersion is an important indicator for the effectiveness of a given intensity measure, i.e., smaller dispersion is always preferred. It was found that the dispersions resulting from scaling to Sde and $S d i$ were quite close. Based on this it can be concluded that considering the dispersions, the use of $S d i$ as an intensity measure does not have an advantage when compared to the use of Sde, for the frames used in this study.

\section{REFERENCES}

[1] J. R. Garcia and E. Miranda, "Performance-based assessment of existing structures accounting for residual displacements," The John A. Blume Earthquake Engineering Center, Department of Civil and Environmental Engineering, Stanford University, Stanford, Calif., 2005.

[2] P. Tothong and N. Luco, "Probabilistic seismic demand analysis using advanced intensity measures," Earthquake Engineering and Structural Dynamics, vol. 36, pp. 1837-1860, 2007.

[3] National Building Code of Canada 2010, Institute for Research in Construction, National Research Council of Canada, Ottawa, Ont., 2010 .

[4] National Building Code of Canada 2005, Institute for Research in Construction, National Research Council of Canada, Ottawa, Ont., 2005.

[5] L. Lin, "Development of improved intensity measures for probabilistic seismic demand analysis," Ph.D. thesis, Department of Civil Engineering, University of Ottawa, Ottawa, Ont., Canada, 2008.

[6] A. J. Carr, "Ruaumoko-Inelastic Dynamic Analysis Program," Department of Civil Engineering, University of Canterbury, Christchurch, New Zealand, 2004.

[7] J. B. Mander, M. J. N. Priestley, and R. Park, "Theoretical stress-strain model for confined concrete," Journal of Structural Engineering, vol. 114, no. 8, pp. 1804-1849, 1988 .

[8] G. M. Atkinson, Personal Communication, 2006.

[9] S. Halchuk, J. Adams, and F. Anglin, "Revised deaggregation of seismic hazard for selected Canadian cities," in Proc. the $9^{\text {th }}$ Canadian Conference on Earthquake Engineering, Ottawa, Ont., pp. 420-432, 2007.

[10] R. Tremblay and G. M. Atkinson, "Comparative study of the inelastic seismic demand of eastern and western Canadian sites," Earthquake Spectra, vol. 17, no. 2, pp. 333-358, 2001.

[11] P. Fajfar, "A nonlinear analysis method for performance-based seismic design," Earthquake Spectra, vol. 16, no. 3, pp. 573-592, 2000.

[12] P. Tothong and C. A. Cornell, "Probabilistic seismic demand analysis using advanced ground motion intensity measures, attenuation relationships, and near-fault effects," PEER Report 2006/11, Pacific Earthquake Engineering Research Center, University of California, Berkeley, Calif., 2007.

L. Lin received her M.A.Sc. (in 2005) and Ph.D. (in 2008) degrees in structural engineering from the Department of Civil Engineering at the University of Ottawa. Her Ph.D. thesis was nominated for Governor General's Gold Medal as the most outstanding Ph.D. thesis in the Sciences at the University of Ottawa.

L. Lin is currently working in the Department of Building, Civil and Environmental Engineering at Concordia University, Canada. Her research is in the fields of structural and earthquake engineering, and focuses on the improvement of the seismic design and performance of buildings, bridges and infrastructure systems.

L. Lin has received a number of prestigious awards including the NSERC postdoctoral fellowship, and visiting researcher fellowship at Stanford University. Dr. Lin is a member of EERI (Earthquake Engineering Research Institute) and CSCE (Canadian Society for Civil Engineering). 